\title{
А.Ю. Коловская
}

\section{КУЛЬТУРНО-КОНТЕКСТУАЛЬНАЯ КОНЦЕПЦИЯ ЯЗЫКА НАУКИ В РАКУРСЕ АНАЛИТИЧЕСКОЙ ФИЛОСОФИИ}

\begin{abstract}
Культурно-контекстуальная концепция языка науки содержит в себе идею языковой креативности, что выявляет проблему гносеологического статуса языка нау$\kappa и$, связанную, в свою очередь, с культурными основаниями языковой онтологии и языковой практики. Современный этап развития науки характеризуется интеграцией, междисциплинарностью. При сохраняющейся на сегодня гипотетичности проблемы концептуализации языка науки представляется интересным его рассмотрение в ракурсе аналитической философии.

Ключевые слова: язык науки, креативность, гносеологический статус, интеграция.
\end{abstract}

Исходной предпосылкой данной статьи стала точка зрения, что культурно-контекстуальная концепция языка науки содержит идею языковой креативности, собственно, под культурно-контекстуальной концепцией понимаются теории, придающие языку науки статус культурного явления, свойством которого является креативность [1. С. 41-70].

Однако языковая креативность составляет проблему и, как собственно понятие, и как идея, обосновывающая гносеологический статус языка науки, поскольку обусловливает противоречивый характер познавательных возможностей последнего.

Для рассмотрения данной проблемы мы избрали историко-философский ракурс, в котором заметно преобладание аналитической философской традиции.

В связи с этим видится целесообразным обращение к традиции философии рубежа XVIII-XIX веков в Германии, представленной в трудах И. Гердера и В. Гумбольдта. По определению М. Соболевой, эти труды являются началом аналитической философии в Германии, традиции, которая затем пресеклась по причине известных событий в XX веке и возвратилась уже после Второй мировой в некотором преобразованном англо-американском виде [2]. Словом, эта изначальная традиция представляет некий общий исток для философии как «критики языка» и сдвигает лингвистический поворот в философии на XIX столетие, тем самым изменяя привычный курс деления на континентальную и аналитическую философии, что дает основания компаративистике и интеграции самих этих подходов [3, 4].

Необходимо заметить, что выражение «креативность языка», хотя и редко, встречается в исследовательской литературе, подчас имеет аксиоматический характер, поскольку значительная часть семантики этого понятия переносится на язык с характеристики личности (человека), субъекта. В этой связи необходимо прояснить данный вопрос как существенный для установления статуса языка науки (гносеологического, ценностного, онтологического). Большинство философских концепций креативности 
рассматривают различные формы активности личности, субъектности, творчества, включая языковую креативность. Является ли креативность чем-то особенным по сравнению с общеупотребительным понятием «активность»?

Посмотрим далее, как в психологии характеризуются такие понятия, как «надситуативная активность» и «поисковая активность». Здесь подчас используются совсем уже близкие к креативности определения. Однако в слове «активность» в основе - акт, действие, а в слове «креативность» - созидание - творение. Креативность характеризуется готовностью к созиданию, продуцированию принципиально нового, поэтому продуктом креативности является только то, что не может быть получено известным методом или алгоритмом действия. Существенным для вопроса языковой креативности являются такие характеристики, как высокая чувствительность к проблемам вообще и к проблемной ситуации, способность объединять и комбинировать разнообразные и многоплановые идеи (информацию). Как показано в исследованиях творчества как психического процесса (Я.А. Пономарёв, В.Н. Дружинин, И. Пригожин, Л.Б. Ермолаева-Томина), со способностью к творчеству связаны два личностных качества: познавательная мотивация и чувствительность к побочным образованиям (мыслям, образам, чувствам, внешним продуктам), которые возникают при мыслительном процессе. Тем самым понятие креативность включает в себя и ценностный аспект, что ставит перед нами задачу определить и ценность самой креативности.

Рассмотрим ряд философских понятий на предмет их эквивалентности друг к другу, поскольку мы находим эти понятия в чем-то близкими, но несомненны и их различия. Итак, понятие креативность в языке и понятие, характеризующее функцию сознания идеаторность. Идеаторность как функция сознания - способность творить и воспроизводить идеи - внутренняя самостоятельная работа, выходящая за рамки простого отражения [5. Гл. 2]. Результатом данной способности явилась выработка системы кодирования передачи и распространения содержания сознания - языка (термин этот введен грузинским философом и социологом Китой Мегрелидзе, слушателем во Фрайберге лекций Гуссерля в 1920-е годы, затем по возвращении репрессированным). То есть язык является производным функции идеаторности сознания. Но воспроизводит ли язык по аналогии то же функциональное свойство? Да, но применительно к языку данное понятие в настоящее время не употребляется. Очевидно, что сознание, производя идеи значений, осуществляет процесс придания смысла. Свойство же языка развиваться, формируя ценностные смысловые коннотации, на наш взгляд, следует обозначить как креативность языка. В подкрепление данной мысли вновь обратимся к гумбольдтовскому определению речи как сомыслия [6]. В первичном семантическом фокусе Гумбольдта язык «производит» мысль, даже если как нечто «всегда мимолётное» и непременно в разговоре друг-с-другом, т. е. как совместную работу. Работа языка - это дело, или Poiesis. Далее же, как подмечает Юрген Трабант [7], у Витгенштейна мы можем встретить утверждение, что язык, под первично прагматическим углом зрения, как действие друг-сдругом, как практика, прежде всего не создает ничего вне самой совместной работы. Поэтому он первично «игра», а не работа: туда и обратно, как в игре в шахматы [8. С. 193]. Витгенштейн словно бы отказывает языку в самостоя- 
тельной креативной составляющей, но в то же время, что есть понятие игры? Очень часто мы можем встретить определения - свободная игра как творчество, или, наоборот, творчество как свободная игра. В конце концов, важно, что оба философа, и Гумбольдт, и Витгенштейн, считают употребление языка решающим для мышления и речи. Определение креативности свойством языка скорее соответствует определению языка по-гумбольдтовски, как поэзиса, что, в свою очередь, не совсем аналогично идеаторности как творческой функции сознания. И уже благодаря несовпадению контекстов этих двух близких понятий очевидна их неэквивалентность.

Далее, предлагаю сравнить понятие «креативность» с понятием «эмерджентность», введенным в употребление лингвофилософией сравнительно недавно [9. С. 50]. Следует отметить, что оба понятия используются в философии благодаря процессам междисциплинарной интеграции. Первое, в связи с кризисом креационизма в философии в Новое время, обрело себя в психологии и затем вновь нашло применение, к примеру, в математической теории недетерминированной вычислимости [10. С. 80]. Второе заимствовано лингвистикой из теории систем, поскольку эмерджентность - свойство любой системы, присущее целому, но не встречающееся в частях [11. С. 70]. В актуальной беседе философ и лингвист Павел Барышников [9] убеждает в значимости принципа эмерджентности в лингвистике, который позволяет «ослабить» методологическое напряжение объяснительного разрыва в онтологических вопросах языка и сознания, а также избежать линейной нисходящей каузации и редуктивного физикализма. Вышеуказанный тезис «о значимости принципа эмерджентности» вполне, казалось бы, применим и к понятию языковой креативности [12. С. 55]. Но нет, здесь не скажешь об эквивалентности понятий, и, по всей видимости, оттого, что в коннотативном плане оба понятия содержат фрагменты онтологических оснований наук и дисциплин их произведших. Более того, их смысловое несовпадение, на мой взгляд, следует рассматривать в диалектике детерминизма и индетерминизма. Понятие «эмерджентность» заключает стремление преодолевать детерминистские принципы онтологических оснований физики, т.е. тяготеет к нередуктивному физикализму, будучи тем не менее одной природы с этими основаниями. А понятие «креативность» введено с необходимостью преодолевать линейный эволюционный детерминизм в понимании принципа развития, лежащего в основаниях наук, таких как, например, биология, психология. Этот же принцип развития не присущ, по определению академика В.С. Степина [13], онтологическим основаниям физики. Тем самым оба понятия демонстрируют, пользуясь его же определением, «социокультурную размерность» на постнеклассическом этапе науки.

Креативность языка создаёт противоречие в вопросе статуса языка в познании, потому что обнаруживает связи с серьезными проблемами в науке. Это и проблемы истины, понимания, интерпретации. Креативность стремится к новизне, попирая в этом стремлении традицию, создавая драматизм в науке. Креативный язык не методичен и не нормативен. Он устремлён в бесконечное разнообразие смыслов, и невозможно оставаться уверенным в том, что сказанное и есть то, что следовало сказать. Креативный язык порождает но- 
вые принципы научной деятельности и утверждает посредством слова культурный образ мысли, культурную символику слова, культурную ценность.

Язык является не только важным аспектом методологии современной науки, но и проблемой множества наук о самом языке как объекте познания.

Что собой представляет язык науки и в чём его особенности в сравнении с другими языками? Прежде всего - это система понятий. Как система понятий язык науки (в идеале) отличается точностью и однозначностью. Как символическая система язык науки имеет собственное (символическое) содержание. Эта система способна использовать для представления знания или описания объекта модели, образы, что позволяет обнаруживать в реальности что-то неявное, не лежащее на поверхности, непредсказуемое. Если, например, культура - это групповой способ структурирования мира, чтобы избежать хаоса и обеспечить выживание группы, то язык - это система символов, которая представляет и отмечает это структурирование [14]. Может ли быть обыденное понимание адекватным в том, что такое язык науки? Ведь сама наука сомневается в существующих определениях и в их необходимости, полезности и даже в «существовании самой реалии»- языка науки. Проведя анализ существующих определений языка науки, многие исследователи обращаются к логике, анализируют лингвистические и некоторые другие подходы. Так, Н.В. Бугорская обосновывает неопределённый вывод о том, что ни представления об этническом языке в лингвистике, ни определения функционального свойства, ни различные способы отождествления языка с типом мышления не проясняют понятие «язык науки». Также идеи существования языков различных наук, различных сфер деятельности оставляют в стороне поиски универсального языка научного общения. Поиски связи языка науки с естественным языком, по мнению автора, могут привести только к их противопоставлению, что указывает на искусственность образования понятия «язык науки», подобно языку эсперанто. К тому же о необходимости отграничения языка науки от обыденного языка говорилось ещё в раннем позитивизме и много ранее. Здесь мы встречаемся с точкой зрения о тупиковом состоянии научных изысканий в области единого языка науки, или метаязыка. Однако проблемы единства языка науки и проблемы единства национального языка полагаются не без основания «старыми». Например, полагая, что изначальное единство мира обусловлено временем, языком и множеством отдельностей, В. Хлебников в заметках, относящихся к 1922 году, утверждал, что главная цель труда художников и труда мыслителей - создать общий письменный язык, общий для всех народов третьего спутника Солнца, построить письменные знаки, понятные и приемлемые для всей населённой человечеством звезды ${ }^{1}$. Однако эти «старые» проблемы и характеризуют языковую проблематику во всей гуманитарной науке в XX и XXI вв. Работа Н.В. Бугорской завершается утверждением не в пользу создания единого языка науки: «Двигаясь в этом направлении, научная мысль неизбежно уходит в сторону от решения проблем научной коммуникаџии: вместо признания существования множества «научных языков» и постановки проблем, связанных с этой множественностью, вместо замены унифицирующей мо-

\footnotetext{
${ }^{1}$ Имеется в виду заметка «Художники мира!».
} 
дели научного взаимодействия диалогической, терминоведы занимаются фетииизацией языка» [15].

Между тем «терминоведы» появились в теории познания и в философии языка не сегодня. И здесь мы вступаем в полосу противоречия с западной исторической антропологией в лице Кристофа Вульфа, который считает этот процесс начинающимся от исходных представлений не-языкового познания у Платона. Затем в начале модерна мы наблюдаем этот процесс посредством разнородных оценок роста значения народных и национальных языков у Бэкона, Локка и Кондильяка, с одной стороны, и Лейбница, Гердера и Гумбольдта - с другой. Далее достигаем позиций, которые, как у Хомски, подчеркивают важность генетически укорененной универсальной речевой способности, или, как у Витгенштейна, считают употребление языка, в бесконечном количестве языковых игр, решающим для мышления и речи. Как далее отмечает К. Вульф, «...в глобальной перспективе в прошедшем столетии отмерли сотни языков. В результате сокращается многообразие человеческого духа. Намечающееся возникновение нового универсального языка науки и техники поддерживается унифицирующими тенденциями глобализации. Несмотря на значительное сопротивление, это также повлечет за собой редукцию культурного многообразия. Следствия здесь вряд ли предсказуемы; но они приведут в дальнейшем к весомым изменениям в самопонимании человека» [8. С. 193].

Отец Павел Флоренский, вошедший в плеяду учёных, обладающих необозримой широтой взглядов и универсальностью, может быть отнесён к исследователям, рассматривающим язык науки как систему терминов. В работе «Имена» П. Флоренский утверждает, что изучение терминологии какой-либо науки есть изучение её истории, так как она и есть система терминов. Здесь следует разобраться, поскольку с каждым годом объемы исторического возрастают. Как показано у А.П. Назаретяна, бесконтрольный рост разнообразия за границей оптимального снижает способность динамической системы к эффективному внутреннему управлению. «Если бы разнообразие было безусловной ценностью (как подчас трактуют закон Эиби), то языку, например, не нужна бы была единая грамматика, школе - учителя словесности, а издательству - редакторы и корректоры. Обществу не нужны были бы мораль, уголовный кодекс, правоохранительные органы, правила дорожного движения $и$ m.д.» [16. С. 9]. Даже мышление людей за границей оптимального разнообразия утрачивает свои свойства.

Многочисленные факты выработки в природе и социальной среде сложных механизмов сдерживания видового и поведенческого разнообразия указывают на отсутствие исключительной самоценности разнообразия. Полученный в 80-е годы в результате изучения соотношения разнообразных характеристик в системах любого рода закон иерархических компенсаций существенно дополняет закон необходимого разнообразия. Его общая формулировка, по Назаретяну, выглядит так: рост разнообразия на верхнем уровне иерархической организации обеспечивается ограничением разнообразия на предыдущих уровнях, и, наоборот, рост разнообразия на нижнем уровне разрушает верхний уровень организации. Данная закономерность проявляется во всех сферах человеческой деятельности. Он пишет: «B языке ограничение до- 
пустимых фонемных комбинаџий совершенно необходимо для построения слов, ограничение синтаксических сочетаний - для построения фраз и т.д. Исторически это вело к укрупнению и обобщению языковых правил ... Развитие науки требует упрощающих обобщений, в которых имплищитно содержится (и может быть дедуктивно выведено) множество фактов, причинных связей, достоверных суждений прогнозов и рекомендаций, но вместе с тем исключается множество других фактов, гипотез и т.д. ... Наоборот, с упразднением грамматических регламентаций языковая система деградирует, затрудняя взаимопонимание, расчленяя языковое сообщество и нарушая совместную деятельность» [16. С. 9].

Разнообразие языка науки в аспекте терминообразования констатирует креативность. Семиотическая, лингвистическая, логическая и некоторые другие составляющие языка определяют его статус в науке. Однако статус языка науки постоянно меняется в связи с новыми данными как многочисленных исследований, так и языковой практики, обогащённой коммуникационными процессами. Приведём суждение Х.-Г. Гадамера: «Научная речь - это всегда опосредствующее звено между спещиализированным языком, или спещиализированныли выражениями, называемыми научной терминологией, и языком живым, растущиим и меняющимcя [17]. А поворот мышления к диалогу, как необходимости для понимания и усвоения иных языков, логик, убеждений, выводов, суждений, расширяет исследовательское поле в языковой проблематике. Рост разнообразия создаёт условия для проявления языковой креативности. Накапливая ресурс разнообразия в течение столетий, язык достиг состояния, когда встала проблема ограничения разнообразия. Под разнообразием языка науки имеются в виду гипотезы, прогнозы, экстраполяции, интерпретации, языковые игры, стереотипы, модели, логики, шаблоны, термины, понятия, определения, дискурсивные практики и пр.

Правомерно предположить, что язык науки равно требует и выработки точных языковых форм, и погружённости в материал конкретных наук, отвечает на реальности, складывающиеся в теории и философии познания (позитивные, негативные, спорные и пр.). Как показано в исследовании роли языка в коммуникационных тенденциях глобального мира, такими реальностями являются следующие:

- Коммуникативный дискурс как новая рациональность. Дискурс - высшая форма научной дискуссии, стремящаяся приобщить к развитой теории широкий круг народных масс (постаналитическая философия Ю. Хабермаса).

- Выделение дискурсивных порогов знания. Коммуникация людей есть языковая игра, ведущая к выработке интерсубъективного решения (зрелый дискурс).

- Тенденция восхождения от поиска устойчивости в языке к агонистике языковых игр (Ж.-Ф. Лиотар). Акцент на многообразии языковых игр и дискурсов (в постструктурализме) (М. Фуко).

- Плюрализм языковых игр, который невозможно отрицать при существующем в науке обилии гипотез и теорий.

- Языковая релятивность и языковая игра - это сложная форма межличностной коммуникации с неординарной концептуальностью. Однако данная сложность может и должна быть осмыслена и подвергнута научному анализу [18].

Рассмотрение тенденций в современной коммуникации, где первостепенное значение имеет язык, было бы неполным вне контекста аналитической 
и постаналитической философии, хотя это и требует отдельного анализа. Язык науки проявляет себя не только в печатном слове, но, значительным образом, в трансляциях, коммуникациях, диалогах, монологах - звучащей речи. В постаналитической философии вербальные и невербальные средства также обозначаются языком. В науке активно используются информационные ресурсы (информационный сервер, анализирующие программы, автоматизированные тестовые методики, компьютерный документооборот). Возникает виртуальная сеть со всей присущей атрибутикой: цитирование, ссылки, справочники, визуализация, тематические переходы, консультации, композицирование и редактирование текстов и др. Между ними существует коммуникативная связь.

Проблема языка в контексте аналитической философии имеет принципиально новое, предельно расширительное видение языковой реальности. Именно в аналитической и постаналитической философии актуализированы понятия, относящиеся к языку. К такого рода понятиям могут быть отнесены: интерпретация, текст-структура, понимающая коммуникация, языковые игры (Л. Витгенштейн, Т. Апель), языковая рефлексия, метаязык, нарратив, пастиш, как форма речевого самовыражения, иронизм, эпистемологический бихевиоризм (Джеймисон, Р. Рорти), трансиендентальная и универсальная прагматика и семиотика (Т. Апель, Ю. Хабермас) и многое другое.

Уже простое перечисление терминологического ряда показывает, как близко стоит аналитическая философия к проблемам глобализации, коммуникации, языковой реализации. И, в свою очередь, как близко стоит к ней философия языка, с его проблемой интертекстуальности, нарративной референции и означивания языковых игр. И, конечно, с тенденциями рассмотрения языка в качестве творческой процессуальности, определяющей духовное бытие человека и совпадающей с ним.

История науки показывает, что предмет познания может развиваться, обретать новые формы и содержание. При этом всегда наблюдается выход (трансцендирование) за пределы понятийно-классического языка. Например, есть словарь медиаобразовательных терминов. Сложился и продолжает складываться словарь информатики и т. п. Относительно рассматриваемого вопроса обратим внимание на создание «проективного философского языка». Опубликовано первое издание «Проективный философский словарь: Новые понятия и термины» под редакцией Г.Л. Тульчинского и М.Н. Эпштейна (2003 г.). Это особый, порождающий жанр философского дискурса, содержащий термины и понятия, впервые предлагаемые для употребления. В словаре отражены интеллектуальные, культурные, технические, социальные процессы, характерные для начала третьего тысячелетия. Как отмечает М.Н. Эпштейн, обычный путь терминов - от использования в конкретных текстах - к фиксации и систематизации в словаре. Данные инициативы указывают на то, что никакая наука не может развиваться без обновления своей концептуально-терминологической системы. Переход к креативному синтезу языка, к системному построению новых понятий и терминов есть новый поворот науки XXI века.

Проблема гносеологического статуса связана с культурными основаниями языковой онтологии и языковой практики. Язык науки - сложная категориальная система, обладающая модальностью, языковыми значениями, целостностью представлений о мире и многими другими материальными и идеальными сущ- 
ностными признаками. Обновление смыслов, движение текстов и контекстов, незавершённость мысли в высказанном слове, неисчерпаемость понимания, бесконечность интерпретации, обсуждаемые в теории и философии языка, оставляют открытой концептуальную систему «Язык - креативность - познание». Креативность языка как такового обусловливает качество и роль языка науки, различающего жизненные и научные истины не как отдельности, но как феномены, взаимосвязанные в экзистенциальном значении.

Но тут возникает вопрос о ценности языковой креативности. Если бесконтрольный рост разнообразия снижает внутреннюю управляемость и динамичность системы, а язык в своей креативной сущности творит разнообразие и принуждает воспринимать и отзываться на него, то креативность языка науки может создавать множество проблем на пути разрешения противоречия между знанием и незнанием. Философия языка развивалась как критика языка. Примеров отказа от языка в пользу непосредственного опыта восприятия реальностей в настоящем и прошлом в науке достаточно. Проблема состоит в языковом принуждении восприятия опыта, новизны и неисчерпаемости креативного потенциала языка в их интерпретации, описании, представлении. Сопоставление разных исследовательских перспектив облегчает осознание и преодоление неизбежной односторонности специальных точек зрения на язык науки. Современный этап развития науки характеризуется интеграцией, междисциплинарностью. Способен ли язык транслироваться в смежные науки без существенного изменения семантических значений? При сохраняющейся на сегодня гипотетичности проблемы концептуализации языка науки представляется интересным его рассмотрение в ракурсе аналитической философии.

В заключение следует сказать, что исследователи языка науки в контексте его познавательного статуса на протяжении более чем векового отрезка времени говорят о внутреннем потенциале языка, модификациях смысла, развитии философского дискурса, что даёт основания для закрепления за языком свойства креативности. В современных дискуссиях относительно связи между языком и мыслительным процессом, между языком и действием, языком и пониманием, языком и терминообразованием, естественным языком и языком науки, языком науки и искусственными языками содержатся обоснованные идеи, позволяющие рассматривать познавательный ресурс языка на основе потенциала креативности.

Изложенные выше взгляды философов, представляющих аналитическую традицию во взглядах на познание, метод, истину, язык подсказывают вывод о том, что креативность языка как такового (естественного, народного, обыденного) обусловливает качество и роль языка науки, различающего жизненные и научные истины не как отдельности, но как феномены, взаимосвязанные в экзистенциальном значении.

Нескончаемое обновление смыслов, движение текстов и контекстов, и многие другие открытия в теории и философии языка оставляют открытой концептуальную систему «Язык - креативность - познание». Один из наиболее оптимальных путей разрешения проблемы языковой креативности в современной философии языка лежит через возвращение к гумбольдтовской традиции интерпретации языка и интеллектуальной активности человека как энергии. 
Не возникает сомнений в своевременности исследований роли креативности в познавательном статусе языка с самыми разнообразными подходами, и аналитический подход здесь занимает ведущие позиции. Как интеграция становится доминантой развития науки, так и креативность становится доминантой развития языка науки.

\section{Литература}

1. Человек. Наука. Ценности: кол. мон. / отв. ред. В.И. Кудашов. Красноярск: Сиб. федер. ун-т, 2015. $268 \mathrm{c.}$

2. Соболева М.Е. Философия как «критика языка» в Германии. СПб.: Изд-во С.-Петерб. ун-та, 2005. 412.

3. Васильев В.В. Сознание и вещи. Очерк феноменалистической онтологии. М.: Либроком, 2012.

4. Шиян А.А. [Рец. на кн.:] В.В. Васильев. Сознание и вещи. Очерк феноменалистической онтологии // Вопросы философии, 2015. № 2. С. 201-205.

5. Мегрелидзе K.P. От животной ступени сознания к человеческому мышлению // Основные проблемы социологии мышления. Изд. 3. М.: URSS. 2007. 488 с. Гл. II.

6. Гумбольдт В. Язык и философия культуры. М.: Прогресс. 1985. 343 с.

7. Trabant Jü. Mitridates im Paradies. Kleine Geschichte des Sprachdenkens. Münhen, 2003.

8. Вульф Кристоф. Антропология: История, культура, философия / пер. с нем. Г. Хайдаровой. СПб.: Изд-во С.- Петерб. ун-та, 2008. 280 с.

9. Барышников П.Н. Становление лингвистики как самостоятельной науки // Вестник РУДН, серия «Философия». 2009. № 3. С. 50-57

10. Анисов А.М. Креативная недетерминированная вычислимость // Вестник Российского университета дружбы народов (РУДН), серия «Философия». 2009. № 3. С. 80-93.

11. Чеклеиов В.В. Динамические эмерджентные интерфейсы сложных социотехнических систем // Философские проблемы информационных технологий и киберпространства № 1(9), июнь 2015. URL: http://cyberspace.pglu.ru/issues/detail.php?ELEMENT_ID=98188 (дата обращения: 23.04.16).

12. Михайлова O.A. Креативные практики языковой личности. Креативность в терминологии // Уральский филологический вестник. Серия: Язык. Система. Личность: Лингвистика креатива. 2012. Вып. № 3.

13. Стёпин В.С. Основания науки и их социокультурная размерность // Научные и вненаучные формы мышления. Симпозиум. Москва; Киль, 1996.

14. Маиумото Д. Культура и язык. СПб.: прайм - Еврознак, 2002. С. 256-276.

15. Бугорская Н.В. Об определении понятия язык науки // Научный вестник МГТУ ГА: сер. Междун. деят. высш. шк. 2006. № 102. С. 81

16. Назаретян А.П. Смыслообразование как глобальная проблема современности: синергетический взгляд // Вопросы философии. 2009. № 5.

17. Гадамер X.- Г. Истина и метод. Основы философской герменевтики. М., 1988.

18. Коловская А.Ю. Коммуникационные тенденции глобального мира и язык науки // Актуальные проблемы глобалистики и геополитики. Красноярск, 2012. С. 269-277.

Kolovskaya Anna Yu. Siberian Federal University (Krasnoyarsk, Russian Federation) DOI: $10.17223 / 1998863 \mathrm{X} / 34 / 9$

CULTURAL-CONTEXTUAL CONCEPT OF THE LANGUAGE OF SCIENCE FROM THE PERSPECTIVE OF ANALYTIC PHILOSOPHY

Keywords: the language of science; creativity; epistemological status, integration

The background for this paper is the view that cultural-contextual concept of the language of science contains the idea of linguistic creativity. However, the idea of creativity gives the language of science epistemological status. Cultural-contextual concept includes theories imparting the status of a cultural phenomenon to the language of science. The problem of the epistemological status is related to the cultural foundations of the linguistic ontology and language practice. The wider presentation of this aspect as the linguistic variety (creativity) raises a question of the value of linguistic creativity. If the uncontrolled increase of variety brings down the inner controllability and dynamic characteristics of the system. So the creativity in the language of science is able to cause a large number of problems in the process of resolving the conflict between knowledge and ignorance. The philosophy of language 
has been developing as a critique of language. There are many cases of the preference for the reality direct perception to language expression throughout the history of science. The problem is any language forces the particular experience preventing it from novelty and freshness of the experience perception through interpretation, description and representation. Comparison across different research perspectives facilitates understanding and overcoming the inevitable parochialism of the particular language of sciences. The current stage of the scientific development is characterized by integration and multidisciplinarity of the research. Is the language able to be transmitted to the other branch of science without some significant changes of semantics? This question seems interesting to consider from the perspective of analytical philosophy taking into account the hypothetical problem of the language of science conceptualization.

\section{References}

1. Kudashov, V.I. (2015) Chelovek. Nauka. Tsennosti [People. Science. Values]. Krasnoyarsk: Siberian Federal University.

2. Soboleva, M.E. (2005) Filosofiya kak "kritika yazyka" v Germanii [Philosophy as a "critique of language" in Germany]. St. Petersburg: St. Petersburg State University.

3. Vasiliev, V.V. (2012) Soznanie i veshchi. Ocherk fenomenalisticheskoy ontologii [Consciousness and Things. An Essay on Phenomenalistic Ontology]. Moscow: Librokom.

4. Shiyan, A.A. (2015) V.V. Vasil'ev. Soznanie i veshchi. Ocherk fenomenalisticheskoy ontologii [V.V. Vasiliev. Consciousness and Things. An Essay on Phenomenalistic Ontology]. Voprosy filosofii. 2. pp. 201-205.

5. Megrelidze, K.R. (2007) Osnovnye problemy sotsiologii myshleniya [Main problems of sociology of thinking]. 3rd ed. Moscow: URSS.

6. Humboldt, V. (1985) Yazyk i filosofiya kul'tury [Language and Philosophy of Culture]. Translated from German by A.V. Gulyga, G.V. Ramishvili. Moscow: Progress.

7. Trabant, Jü. (2003) Mitridates im Paradies. Kleine Geschichte des Sprachdenkens [Mitridate in Paradise. A Brief History of Language Thinking]. Munich: C.H. Beck Verlag.

8. Wolff, C. (2008) Antropologiya: Istoriya, kul'tura, filosofiya [Anthropology: History, Culture, Philosophy]. Translated from German by G. Khaydarova. St. Petersburg: St. Petersburg State Universuty.

9. Baryshnikov, P.N. (2009) Philosophical Problems of Linguistics. Vestnik RUDN, seriya "Filosofiya" - Bulletin of Peoples' Friendship University of Russia. Philosophy. 3. pp. 50-57. (In Russian).

10. Anisov, A.M. (2009) Creative Nondeterministic Computability. Vestnik RUDN, seriya "Filosofiya" - Bulletin of Peoples' Friendship University of Russia. Philosophy. 3. pp. 80-93. (In Russian).

11. Chekletsov, V.V. (2015) Dinamicheskie emerdzhentnye interfeysy slozhnykh sotsiotekhnicheskikh sistem [Dynamic emergent interfaces of complex socio-technical systems]. Filosofskie problemy informatsionnykh tekhnologiy i kiberprostranstva - Philosophical Problems of Information Technology and Cyberspace. 1(9). [Online] Available from: http://cyberspace.pglu.ru/issues/detail.php?ELEMENT_ID=98188. (Accessed: 23rd April 16).

12. Mikhaylova, O.A. (2012) Kreativnost' v terminologii [Creativity in terminology]. Ural'skiy filologicheskiy vestnik. Seriya: Yazyk. Sistema. Lichnost': Lingvistika kreativa - Ural Journal of Philology. 3.

13. Stepin, V.S. (1996) [Grounds of science and their socio-cultural dimensions]. Nauchnye $i$ vnenauchnye formy myshleniya [Scientific and non-scientific form of thinking]. Proc. of the International Symposium. Moscow. 4-9 April 1995. Moscow; Kiel. (In Russian).

14. Matsumoto, D. (2002) Kul'tura i yazyk [Culture and Language]. Translated from English. St. Petersburg: Praym - Evroznak. pp. 256-276.

15. Bugorskaya, N.V. (2006) Ob opredelenii ponyatiya yazyk nauki [On the definition of the language of science]. Nauchnyy vestnik MGTU GA: ser. Mezhdun. deyat. vyssh. Shk - Scientific Bulletin of Moscow State Technical University of Civil Aviation. 102. pp. 81.

16. Nazaretyan, A.P. (2009) Smysloobrazovanie kak global'naya problema sovremennosti: sinergeticheskiy vzglyad [Meaning-making as a global problem of modernity: A synergistic view]. Voprosy filosofii. 5.

17. Gadamer, H.-G. (1988) Istina i metod. Osnovy filosofskoy germenevtiki [Truth and Method. Fundamentals of Philosophical Hermeneutics]. Translated from German. Moscow: Progress.

18. Kolovskaya, A.Yu. (2012) Kommunikatsionnye tendentsii global'nogo mira i yazyk nauki [Communication trends of the global world and the language of science]. In: Pfanenstil, I.A. \& Yatsenko, M.P. (eds) Aktual'nye problemy globalistiki i geopolitiki [Topical problems of global studies and geopolitics]. Krasnoyarsk: Siberian Federal University. pp. 269-277. 